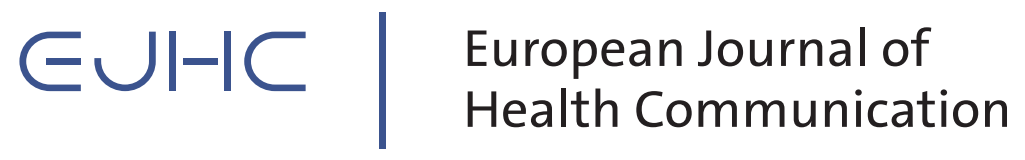

ISSN 2673-5903

ejhc.org

Editorial

Special Issue on Social Aspects of Health Communication

\title{
Social Aspects of Health Communication - Towards a Research Agenda
}

DOI: $10.47368 /$ ejhc. 2021.200

2021, Vol. 2(2) I-IV

CC BY 4.0

\section{Sarah Geber (iD), Tobias Frey (D), Thomas N. Friemel \\ Department of Communication and Media Research, University of Zurich, Switzerland}

Health and health-related behaviours are embedded in social contexts in various ways which comprise both risks and opportunities for an individual's health (Sallis \& Owen, 2015). Communicable diseases, such as COVID-19, influenza, or HIV, spread through social contact between persons (e.g., Rothenberg et al., 1998), and unfavourable health behaviours tend to be reinforced in personal social networks (Valente, 2010). At the same time, social support can help individuals cope with illness in everyday life (e.g., depression; Peirce et al., 2000), and social norms may promote favourable health behaviours (e.g., eating healthily; Mollen et al., 2013).

As a result of digitalisation, new platforms modify known social processes or facilitate new dynamics (e.g., Geber \& Hefner, 2019). On social networking sites, the observation of others' health-related behaviours and learning of social norms influence one's own health behaviours (e.g., Beullens \& Vandenbosch, 2016; Geber et al., 2021); applications allow users to track their health behaviours and share their obtained health goals with others (e.g., Kristensen \& Ruckenstein, 2018); and in online forums, people disclose personal experiences, exchange information, and receive support regarding specific health issues (e.g., Barak et al., 2008). Since these social processes unfold their effects through communication, they deserve special attention from health communication scholars to maintain and improve individual and public health.

Against this background, we suggest a research agenda on social aspects of health communication. Owing to the complexity of individuals' social contexts, this research agenda must address questions lying at the individual, interpersonal, and societal levels. At the individual level, we need to better understand individual health behaviours and their interrelations with individual characteristics and health communication. Which health behaviours are especially susceptible to social influence (e.g., private vs. public health behaviours) and what role do different means of communication play in these contexts? How are individual social characteristics, such as traits (e.g., need to belong), cognitions (e.g., perceived norms), and motives (e.g., need for social 
integration) associated with health behaviours and health-related communication? How are media messages that address social aspects of health behaviour (e.g., social frames) elaborated?

At the interpersonal level, we may investigate the roles of social settings and social relations in the context of health communication. How relevant are different settings for health communication (e.g., family, colleagues, self-help groups)? What roles do different actors (e.g., doctors, patients, bystanders) play and what social roles (e.g., opinion leaders, influencers, followers) exist in the context of health communication? How does health-related interpersonal communication differ depending on the channel or platform (e.g., face-to-face vs. mediated)?

At the societal level, we address questions regarding social systems and structural patterns that affect health and health communication. Which sociocultural aspects (e.g., collectivistic vs. individualistic societies) and characteristics of the media system are relevant regarding health and health communication? What kinds of inequalities related to health communication exist in societies and what are their consequences (e.g., digital inequalities)? How can societal inequalities be addressed by health communication and what guidelines are helpful for journalists to ease these issues?

Furthermore, the research agenda must address methodological challenges to capture the social aspects. This includes both research designs and analytical methods. While some research questions may be answered by asking individuals about their perceptions of others' behaviours (e.g., perceived social norms), other topics require insights into the structure and characteristics of a social network (Friemel, 2021).

With this research agenda in mind, the European Conference on Health Communication, held from 13 to 15 November 2019 in Zurich, was dedicated to a thematic focus on social aspects of health communication. The conference stimulated insightful discussions on theories, methods, and findings relating to social aspects of health communication. With this special issue of the European Journal of Health Communication, we want to continue and extend this fruitful discussion. Of course, the special issue can only address a limited part of the comprehensive research agenda, but we are happy to present four papers that cover different and highly relevant aspects of this understudied perspective.

Stigmatisation is a central aspect of the social dimension of health communication, as it points to social processes of exclusion that must be prevented by anti-stigma communication. Two articles in the present special issue are dedicated to this topic and examine factors of public stigmatisation in different contexts. The article by Röhm, Möhring, Grengel, and Hastall (2021) addresses the topic of self-disclosure of physical disability in online postings via a study examining how this affects stigmatisation on the part of the reader. The online experiment revealed that factors on the sides of both the blogging disabled person and the reader were crucial regarding stigmatisation. Ultimately, the disabled blogger's self-disclosure and the reader's perspectivetaking ability reduced social distance.

Möhring, Krick, and Ditze (2021) address stigmatisation in the context of mental illness by examining how depictions of different characteristics of people with mental illness influence stigma-related attitudes. In their online experiment, they found complex interaction effects between the characteristics of both mentally ill people and readers on stigma-related attitudes. Together, the studies of Röhm et al. (2021) and Möhring et al. (2021) demonstrate the general 
potential of the public thematisation of a disability or illness - physical or mental—in mitigating stigmatisation. In light of the widespread use of social media platforms, as well as their accessibility and importance for people with disabilities or illness, these studies indicate the significant potential for efforts that counter stigma with targeted online communication.

The article by Schossböck (2021) investigates health-related decision-making of people with thyroid disease and the role of crowdsourced knowledge and activist content on social networking sites. Drawing on a participatory netnography within activist communities and 33 in-depth interviews, the study identified four decision-making paradigms of the extent of activism and orientation towards expertise or participation, and the article discusses the role of connective action and politicisation in this context. The results provide valuable input for researchers of illness identities as well as practitioners who need to consider different patient types.

Huisman, Cuelenaere, Joye, and Biltereyst (2021) address the methodological question of how social aspects may affect methods applied in health communication research. Concretely, their study examined users' construction of their self-identity in research interviews. Results show that respondents exhibited various impression management behaviours during their interviews, such as proactively demonstrating knowledge, accomplishments, and positive outcomes. This demonstrates the importance of critically reflecting on how social aspects, such as impression management, affect empirical results produced in interview situations.

These articles highlight the variety of theoretical and methodological approaches in the study of social aspects of health communication. They range from stigmatisation to collective action to impression management and from experimental designs to netnography and qualitative interviews. Regardless of their theoretical and methodological approaches, they underline the importance of focusing on social aspects to better understand the phenomena under study - that is, stigmatisation of persons who are physically disabled or mentally ill, the role of social media in decision-making and collective action of people with rare diseases, and the meaning of impression management in interview situations.

By demonstrating the variety of approaches and topics and the relevance of this perspective, the present special issue advances a research agenda that likely will continue gaining importance. The ongoing digitalisation of the media environment and the resulting increasing interconnectedness of producers and users, doctors and patients, and experts and laypersons will sharpen the focus increasingly on social aspects of health communication. With this special issue, we were able to gain important insights on some of the above-raised questions, especially those relating to the individual and interpersonal levels. Other aspects and questions will need further inquiry, particularly sociocultural aspects, given the global dimension of the current COVID-19 pandemic, but future diseases as well, and we look forward to continuing the discussion on social aspects of health communication.

\section{References}

Barak, A., Boniel-Nissim, M., \& Suler, J. (2008). Fostering empowerment in online support groups. Computers in Human Behavior, 24(5), 1867-1883.

https://doi.org/10.1016/j.chb.2008.02.004 
Beullens, K., \& Vandenbosch, L. (2016). A conditional process analysis on the relationship between the use of social networking sites, attitudes, peer norms, and adolescents' intentions to consume alcohol. Media Psychology, 19(2), 310-333. https://doi.org/10.1080/15213269.2015.1049275

Friemel, T. N. (2021). Social networks. In E. Ho, C. Bylund, \& J. van Weert (Eds.), The International Encyclopedia of Health Communication. Wiley.

Geber, S., Frey, T., \& Friemel, T. (2021). Social media use in the context of drinking onset: The mutual influences of social media effects and selectivity. Journal of Health Communication. Advance online publication. https://doi.org/10.1080/10810730.2021.1980636

Geber, S., \& Hefner, D. (2019). Social norms as communicative phenomena: A communication perspective on the theory of normative social behavior. Studies in Communication and Media, 8(1), 6-28. https://doi.org/10.5771/2192-4007-2019-1-6

Huisman, M., Cuelenaere, E., Joye, S., \& Biltereyst, D. (2021). Sensible use(rs) and the construction of self-identity in research interviews. A qualitative exploration of how middleaged and older adults search for and use online health information. European Journal of Health Communication, 2(2), 44-65. https://doi.org/10.47368/ejhc.2021.203

Kristensen, D. B., \& Ruckenstein, M. (2018). Co-evolving with self-tracking technologies. New Media \& Society, 20(10), 3624-3640. https://doi.org/10.1177/1461444818755650

Möhring, M., Krick, N., \& Ditze, A. (2021). The Influence of Social Support and Characteristics of the Stigmatisers on Stigmatising Attitudes Towards People With Mental Illness. European Journal of Health Communication, 2(2), 66-96. https://doi.org/10.47368/ejhc.2021.204

Mollen, S., Rimal, R. N., Ruiter, R. A. C., \& Kok, G. (2013). Healthy and unhealthy social norms and food selection. Findings from a field-experiment. Appetite, 65, 83-89. https://doi.org/10.1016/j.appet.2013.01.020

Peirce, R. S., Frone, M. R., Russell, M., Cooper, M. L., \& Mudar, P. (2000). A longitudinal model of social contact, social support, depression, and alcohol use. Health Psychology, 19(1), 28-38. https://doi.org/10.1037/0278-6133.19.1.28

Röhm, A., Möhring, M., Grengel, M., \& Hastall, M. R. (2021). How self-disclosure in online postings affects female readers' stigmatisation towards mothers with a disability. European Journal of Health Communication, 2(2), 1-20. https://doi.org/10.47368/ejhc.2021.201

Rothenberg, R. B., Potterat, J. J., Woodhouse, D. E., Muth, S. Q., Darrow, W. W., \& Klovdahl, A. S. (1998). Social network dynamics and HIV transmission. AIDS, 12(12), 15291536. https://doi.org/10.1097/00002030-199812000-00016

Sallis, J. F., \& Owen, N. (2015). Ecological models of health behavior. In K. Glanz, B. K. Rimer, \& K. Viswanath (Eds.), Health behavior: Theory, research, and practice (5th ed., pp. 43-64). Jossey-Bass.

Schossböck, J. (2021). Health-related decision-making of people with thyroid disease: The role of connective action and politicisation of illness identities. European Journal of Health Communication, 2(2), 21-43. https://doi.org/10.47368/ejhc.2021.202

Valente, T. W. (2010). Social networks and health: Models, methods, and applications. Oxford University Press. 